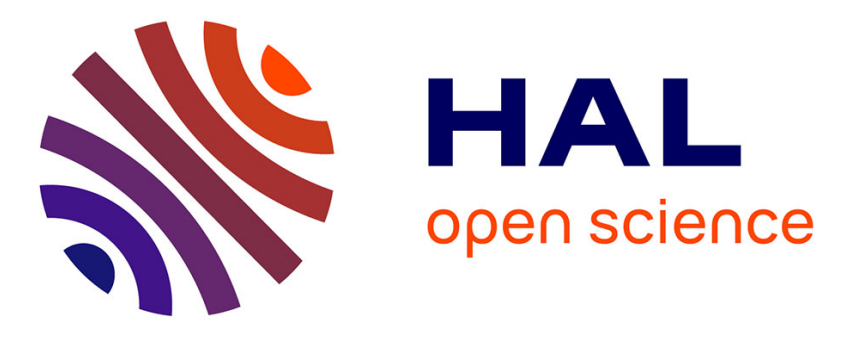

\title{
High Performance and Low Energy Consumption in Phase Change Material RF Switches
}

Alexandre Leon, Bruno Reig, Vincent Puyal, Etienne Perret, Philippe Ferrari, Florence Podevin

\section{To cite this version:}

Alexandre Leon, Bruno Reig, Vincent Puyal, Etienne Perret, Philippe Ferrari, et al.. High Performance and Low Energy Consumption in Phase Change Material RF Switches. 2018 48th European Microwave Conference (EuMC), Sep 2018, Madrid, Spain. pp.491-494, 10.23919/EuMC.2018.8541622 . hal02066763

\section{HAL Id: hal-02066763 https://hal.univ-grenoble-alpes.fr/hal-02066763}

Submitted on 1 Jul 2020

HAL is a multi-disciplinary open access archive for the deposit and dissemination of scientific research documents, whether they are published or not. The documents may come from teaching and research institutions in France or abroad, or from public or private research centers.
L'archive ouverte pluridisciplinaire HAL, est destinée au dépôt et à la diffusion de documents scientifiques de niveau recherche, publiés ou non, émanant des établissements d'enseignement et de recherche français ou étrangers, des laboratoires publics ou privés. 


\title{
High Performance and Low Energy Consumption in Phase Change Material RF Switches
}

\author{
Alexandre Léon ${ }^{\# 1}$, Bruno Reig ${ }^{\# 2}$, Vincent Puyal ${ }^{\# 3}$, Etienne Perret ${ }^{*}{ }^{\circ}$, Philippe Ferrari ${ }^{+5}$, Florence Podevin ${ }^{\sim 6}$ \\ "Univ. Grenoble Alpes, CEA, LETI, F-38000 Grenoble, France \\ "Univ. Grenoble Alpes, Grenoble INP, LCIS, F-26000 Valence, France \\ ${ }^{\circ}$ Institut Universitaire de France, 75005 Paris, France \\ ${ }^{+}$Univ. Grenoble Alpes, Grenoble INP, CNRS, TIMA, F-38000 Grenoble, France \\ Univ. Grenoble Alpes, Grenoble INP, CNRS, IMEP-LaHC, F-38000 Grenoble, France \\ $\left\{{ }^{1}\right.$ alexandre.leon, ${ }^{2}$ bruno.reig, ${ }^{3}$ vicent.puyal $\} @$ cea.fr, ${ }^{4}$ etienne.perret@1cis.grenoble-inp.fr, \\ ${ }^{5}$ philippe.ferrari@univ-grenoble-alpes.fr, ${ }^{6}$ florence.podevin@ grenoble-inp.fr
}

\begin{abstract}
This paper presents a RF to mm-wave switch based on Germanium Telluride phase change material. An integration process compatible with a standard CMOS back end of line is proposed to realize directly heated switches. RF measurements, performed up to $65 \mathrm{GHz}$, show an $O N$-state resistance of $1 \Omega$ with an $O F F$-state capacitance of $7 \mathrm{fF}$ corresponding to a $22 \mathrm{THz}$ cut-off frequency which constitutes a state-of-the-art Figure-of-Merit. Switching time of only $60 \mathrm{~ns}$ in both phase changes allow energy consumption one decade lower than the state-of-the-art for crystallization. A geometrical variation of GeTe dimensions shows a linear evolution of RF performance in terms of $O N$-state resistance and an almost unchanged performance in the $O F F$-state.
\end{abstract}

Keywords - RF switches, phase-change material, GeTe, direct heating.

\section{INTRODUCTION}

Switching is a key function in many RF and mm-wave circuits. In particular, mm-wave applications such as 5G, back-hauling, automotive radars, RF imaging, etc, will require high-performance switches, which are not available yet. From a circuit point of view, performing switches need low insertion loss $(I L)$, outlined by a low $O N$-state resistance $R_{o n}$, and high isolation, outlined by a low $O F F$-state capacitance $C_{o f f}$. As a trade-off, the cut-off frequency $\left(1 / 2 \pi R_{o n} C_{o f f}\right)$ is the major Figure-of-Merit (FoM) for switches; but the switching time, the power consumption, the DC bias voltage, the reliability, and the cost also play a significant role. To address all these requirements, many technologies have been studied during the last decades, such as CMOS and BiCMOS, MEMS, and more recently Conductive-Bridge $(\mathrm{CB})$ or Phase Change Materials (PCM).

CMOS and BiCMOS technologies are limited by their $\mathrm{ON}$ state resistance $R_{o n}$, which leads to pretty high insertion loss. A switch achieving a cut-off frequency of $1.4 \mathrm{THz}\left(R_{\text {on }}=\right.$ $0.5 \Omega$ ) was presented in SOI technology, [1]. Low $R_{\text {on }}$ performance was achieved at the expense of the surface on the die, with a width equal to $1 \mathrm{~mm}$. MEMS switches are very good candidates for low insertion loss with $0.25 \mathrm{~dB}$ at $40 \mathrm{GHz}$ in [2] and $O F F$-state capacitance lower than $10 \mathrm{fF}$ but their reliability and packaging still remain an issue to overcome. CB technology, inspired from CBRAM, constitutes a promising technology, essentially for cost reasons as very simple processes were demonstrated on $\mathrm{PCB}$, for example in [3]. However, integrated CB switches for mm-waves still have to be proven.

Meanwhile, PCMs show outstanding performance in terms of both insertion loss and FoM, with cut-off frequencies over tens of $\mathrm{THz}$, but also extremely low $R_{\text {on }} / R_{\text {off }}$ ratios, especially with GeTe material, where each resistance state is clearly identified and corresponds to a stable material phase: amorphous and crystalline [4]-[7]. Competitors may be GeSbTe [8], but with a lower $R_{\text {on }} / R_{\text {off }}$ ratio and a lower $O N$ state conductivity. Finally, $\mathrm{VO}_{2}$ presents the advantage of requiring low energy as the phase change occurs at $68^{\circ} \mathrm{C}$ only but is unfortunately not bi-stable (crystalline state needs voltage to be maintained), thus reducing the field of applications [9].

When focusing on GeTe based switches, attention has to be paid on their integration, with technological stacks and processes that are CMOS compatible. Both direct [5] and indirect [4] heating can be envisaged. Indirect heating through a heater has proven good performance but may be quite energy consuming, also suffering from a degradation of the heater over the time, thus leading to reliability issues.

In this paper, it is proposed to evaluate the potentialities of a simple technological stack enabling direct heating and high thicknesses of GeTe, which permits to lower the $R_{\text {on }}$ resistance, leading to a high FoM, while drastically reducing the energy consumption for switching.

In part II, the switches fabrication technique and design are described. Emphasis is put on the geometrical parameters that influence the performance. The interest for direct electrical actuation to reduce energy consumption is shown in part III. In part IV, $40 \mathrm{MHz}$ to $65 \mathrm{GHz}$ measurement results are shown. They prove low insertion loss and high Figure-of-Merit. 


\section{FABRICATION \& DESIGN DESCRIPTION}

The process stack is described in Fig. 1. The flow developed so far fulfills two requirements: standard CMOS process compatibility and switching performance. First, compatibility of the materials and techniques with a standard CMOS backend-of-line (BEOL) must be considered for further integration. For instance, neither platinum, nor gold were used, but only aluminum and standard RF silicon materials. Second, different technological stacks were tested to enhance the PCM switch performance. As shown in Fig. 1.b, the PCM is contacted backside using metallic strip lines that optimize electrical contact. Following a strict process flow, aluminum feeding strip lines for backside contact are first patterned on a HRsilicon wafer, after thermal oxidation. Next, GeTe is deposited in a co-pulverization step and patterned thanks to dry etching (RIE). This process allows defining uniform patterns, with width as low as $250 \mathrm{~nm}$. Then a 100-nm thick PECVD SiN dielectric covers and protects GeTe. By the end, a second level of metallic strip lines, etched with a standard RIE, is contacting the first one.

Finally, $\mathrm{SiO}_{2}$ is sputtered for passivation and test pads are opened by RIE.

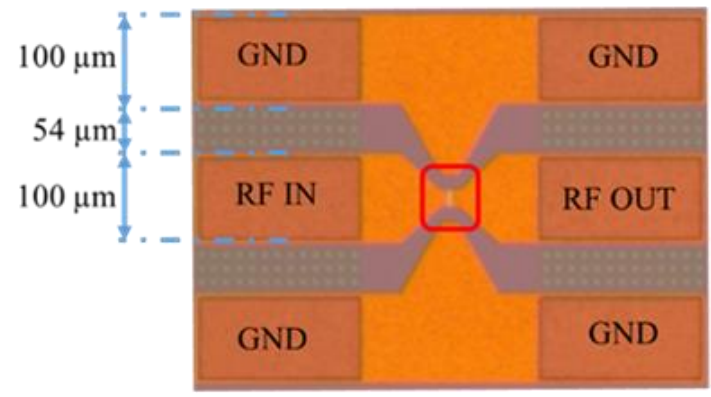

b.

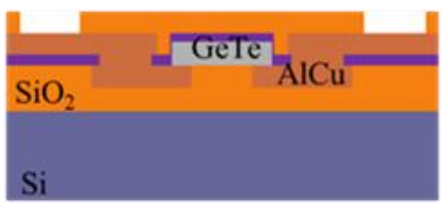

c.

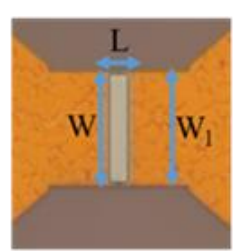

emphasized in Fig. 1.c (20 $\mu \mathrm{m}$ case). All devices are matched to $50 \Omega$. As illustrated in Fig.1.c, the influence of two parameters of the active PCM part were studied in practice, length $(L)$ and width $(W)$.

\section{ELECTRICAL ACTUATION}

After manufacturing, GeTe shows a crystalline phase - low resistivity - due to thermal budget of the technology, so that the first step consists in amorphizing the material.

As mentioned in the introduction, and thanks to the chosen technological stack, direct heating can be performed. A current excitation based on pulses is simply applied via the feeding line to change the phase of the PCM.

Usually, amorphization and crystallization need different excitations shapes, enabling freezing or stabilization of the atomic arrangement, respectively, [4]. In this study, we used the same waveforms for both transitions: a rise time of $5 \mathrm{~ns}$ followed with 50-ns duration time at high-voltage and a fall time of $5 \mathrm{~ns}$. The only difference is the voltage value as the amorphization step needs higher energy. Two conditions must be considered to amorphize the device: i) melting temperature must be reached and, ii) thermal tempering must occur to freeze the material into a messy state. The latter is obtained with the short 5-ns fall time. Meanwhile crystallization step theoretically needs lower energy with a mid-temperature higher than the material crystallization one, but lower than the melting temperature to avoid parasitic amorphization. However, a second phenomenon occurs with direct actuation, i.e. a conductive filament is created if the crystallization voltage is sufficient. To comfort the operation, and after a deep optimization floorplan, it was found that two pulses must be sent to amorphize the device, and three pulses to crystallize it, respectively.

As explained above, several devices with various widths $W$ and lengths $L$ were designed and tested. Also, two thicknesses $t$ of GeTe were compared, $100 \mathrm{~nm}$ and $300 \mathrm{~nm}$, respectively. As seen in Fig. 2, for $L=1 \mu \mathrm{m}$, the necessary programming current to amorphize or crystallize the PCM evolves linearly versus $W$, from $300 \mathrm{~nm}$ to $19 \mu \mathrm{m}$. The electrical current evolution is also proportional to the GeTe thickness.

Fig. 1. a) Optical view of a CPW GeTe switch. b) Technological Stack. c) Close-up on the PCM area with $W$ the width of GeTe and $W_{l}$ the width of CPW line.

CPWs were used as feeding lines. They were designed for 125 or $150 \mu \mathrm{m}$ pitch probes. The width $W_{l}$ of the central strip is $100 \mu \mathrm{m}$. It reduces to 5 or $20 \mu \mathrm{m}$ in the GeTe area as

TABLE I

ENERGY BALANCE IN LITERATURE

\begin{tabular}{|c|c|c|c|c|c|c|c|c|c|}
\hline Paper & $\begin{array}{c}\text { Length } \\
{[\mu \mathrm{m}]}\end{array}$ & $\begin{array}{c}\text { Width } \\
{[\mu \mathrm{m}]}\end{array}$ & $\begin{array}{c}\text { Thickness } \\
{[\mathbf{n m}]}\end{array}$ & $\begin{array}{c}\text { Area } \\
{\left[\mu \mathbf{m}^{2}\right]}\end{array}$ & $\begin{array}{c}\text { Volume } \\
{\left[\mathbf{m m}^{\mathbf{3}}\right]}\end{array}$ & $\begin{array}{c}\text { Amorphization } \\
\text { Energy } \\
{[\mathbf{J}]}\end{array}$ & $\begin{array}{c}\text { Volumic } \\
\text { Energy } \\
{\left[\mathbf{J} / \mathbf{m m}^{3}\right]}\end{array}$ & $\begin{array}{c}\text { Crystallization } \\
\text { Energy } \\
{[\mathbf{J}]}\end{array}$ & $\begin{array}{c}\text { Volumic } \\
\mathbf{E n e r g y} \\
{\left[\mathbf{J} / \mathbf{m m}^{\mathbf{3}}\right]}\end{array}$ \\
\hline El-Hinnawy et al. $[4]$ & 0.9 & 30 & 150 & & $4.0 .10^{-9}$ & $1.2 .10^{-7}$ & 30 & $6.0 .10^{-7}$ & 150 \\
\hline Wang et al. $[5]$ & & & 100 & 24 & $2.4 .10^{-9}$ & $4.5 .10^{-8}$ & 19 & $8.0 .10^{-7}$ & 330 \\
\hline King et al. $[6]$ & 1.3 & 30 & 75 & & $2.9 .10^{-9}$ & $9.0 .10^{-8}$ & 31 & $6.0 .10^{-7}$ & 210 \\
\hline This work & 1 & 4.5 & 300 & & $1.4 .10^{-9}$ & $2.95 .10^{-8}$ & 22 & $2.36 .10^{-8}$ & 17.5 \\
\hline
\end{tabular}




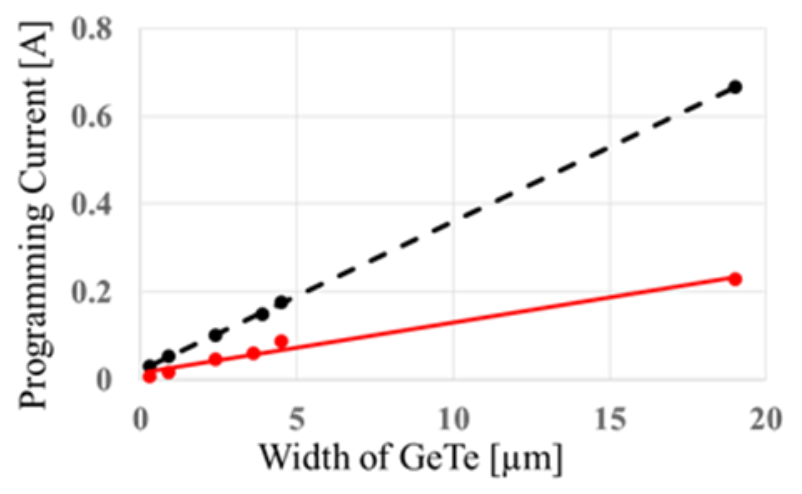

Fig. 2. Programming current for amorphization versus GeTe width $W$. GeTe thickness $t=100 \mathrm{~nm}$ (red solid line), and $t=300 \mathrm{~nm}$ (black dashed line). $L=1 \mu \mathrm{m}$.

The study of the energy consumption during switching was carried out and results compared to the state-of-the-art in table I. The switching energy was calculated as follows: power consumption (activation voltage times current of activation) multiplied by the time duration of the pulse. The comparison with the state-of-the-art is not straightforward, since sizes are somewhat different, that is why a volumic energy was considered, since the current magnitude increases linearly versus dimensions. For amorphization, the volumic energy is similar for all the devices. For crystallization, the consumption of the proposed devices is a decade lower. This very promising consumption is made possible thanks to a performing direct control.

\section{RESUlts}

S-parameters measurements were carried out from $40 \mathrm{MHz}$ to $65 \mathrm{GHz}$ using RF-probes with $150-\mu \mathrm{m}$ pitch. The measurement setup is composed of a semi-automatic probe station, and a Vector Network Analyzer ANRITSU ME7808C. A SOLT (Short, Open, Load, Thru) calibration was performed.

Fig. 3a shows the S-parameters at $O N$ - and $O F F$-states when the device in Fig. 1 is crystallized, and amorphized, respectively, for different widths $W$ and thicknesses $t$ of GeTe. Devices could not be de-embedded, leading to a significant influence of pads and feeding lines at high frequencies above $60 \mathrm{GHz}$.

The insertion loss is constant with frequency in the $O N$ state. It ranges from $-0.1 \mathrm{~dB}$ at $40 \mathrm{MHz}$ to $-0.12 \mathrm{~dB}$ at $65 \mathrm{GHz}$ for $W=19 \mu \mathrm{m}, L=1 \mu \mathrm{m}$ and $t=300 \mathrm{~nm}$, and from $-3.5 \mathrm{~dB}$ at $40 \mathrm{MHz}$ to $-3.6 \mathrm{~dB}$ at $65 \mathrm{GHz}$ for $W=$ $300 \mathrm{~nm}, L=1 \mu \mathrm{m}$ and $t=300 \mathrm{~nm}$, respectively. It is noticeable that the same $I L$ is obtained for the $O N$-state whatever the couple $W=300 \mathrm{~nm}$ and $t=300 \mathrm{~nm}$ or $W=900 \mathrm{~nm}$ and $t=100 \mathrm{~nm}$. Depending on the surface defined by $W$ times $t, I L$ varies between $-0.1 \mathrm{~dB}$ and $-3.5 \mathrm{~dB}$.
Two groups of curves are obtained for the $O F F$-state, with $C_{\text {off }}$ capacitors of $5 \mathrm{fF}$ and $7 \mathrm{fF}$, respectively. The value of $C_{\text {off }}$ is mostly given by metallic feeding lines with an important role played by the fringing electrical field, and corresponds to the two considered widths $W_{l}$, i.e. 5 and $20 \mu \mathrm{m}$, respectively.
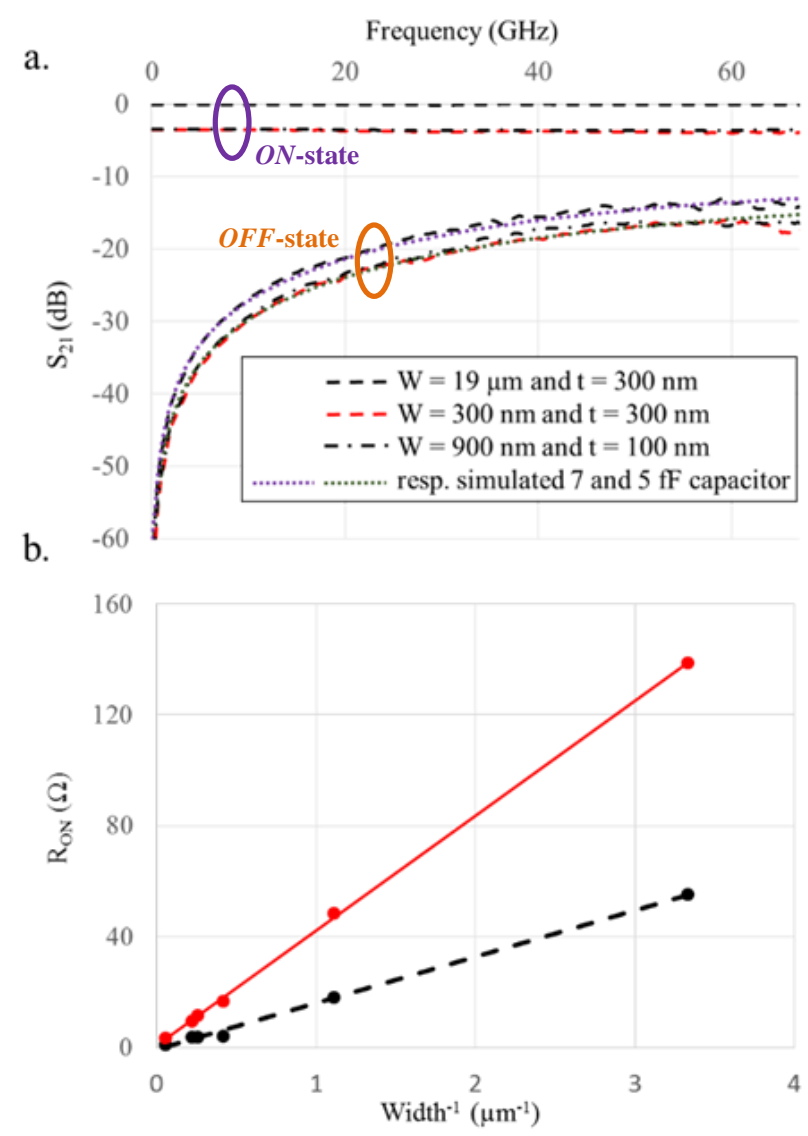

Fig 3. a) Measured $S_{21}$ parameter for various geometries for both $O N$ - and $O F F$-states. b) Evolution of $R_{\text {on }}$ relatively to the inverse of GeTe width (red solid line for $t=100 \mathrm{~nm}$ and black dashed line for $t=300 \mathrm{~nm}$ ). $L=1 \mu \mathrm{m}$.

The $R_{\text {on }}$ resistance is given in Fig. 3b. All the devices present a pure linear resistive behavior versus thickness and width. As direct heating is used, there is no loss added by metallic heating strip line, contrarily to indirect heating. For a $300-\mathrm{nm}$ thick GeTe and a width of $19 \mu \mathrm{m}, R_{\text {on }}$ is equal to $1 \Omega$ (corresponding to $I L$ lower than $0.1 \mathrm{~dB}$ up to $65 \mathrm{GHz}$, as shown above).

The cut-off frequency $\left(F_{c o}\right)$ reaches $22 \mathrm{THz}$ for the best geometry $(W=19 \mu \mathrm{m}, L=1 \mu \mathrm{m}$ and $t=300 \mathrm{~nm})$, with $R_{\text {on }}=1 \Omega$ and $C_{\text {off }}=7 \mathrm{fF}$.

\section{CONCLUSION}

PCM switches based on GeTe were designed, realized and tested up to $65 \mathrm{GHz}$. A geometrical study was performed to evaluate the potentialities of direct heating actuation. The stack simplicity enables to propose thicknesses as high as 
$300 \mathrm{~nm}$, leading to state-of-the-art $O N$-state resistance, leading to a cut-off frequency as high as $22 \mathrm{THz}$. Meanwhile, direct actuation enables to reduce power consumption, with a measured volumic energy for crystallization 10 to 20 times smaller than the usual energy needed by indirect heating. It is interesting to note that with direct actuation, volumic energy for crystallization becomes similar to the one needed for amorphization. Energy consumption is not driven anymore by the long time needed for stabilizing the atomic arrangement as in the indirect heating case. Direct crystallization is assumed to be performed thanks to an efficient creation of a conductive filament.

\section{REFERENCES}

[1] M. Jaffe et al, "Improvements in SOI Technology for RF Switches," in 2015 IEEE $15^{\text {th }}$ Topical Meeting on Silicon Monolithic Integrated Circuit in RF Systems (SiRF) , 26-28 Jan 2015.

[2] [2] F. Souchon, et al., "Thin film Packaged Redundancy RF MEMS Switches for Space Applications," in IEEE 19th International
Conference on Solid-State Sensors, Actuators and Microsystems, Transducers, Taiwan, 18-22 June 2017.

[3] [3] E. Perret, et al., "Realization of a Conductive Bridging RF Switch Integrated onto Printed Circuit Board," Progress In Electromagnetics Research, Vol. 151, 9-16, 2015.

[4] [4] P. Borodulin, et al., "Recent Advances in Fabrication and Characterization of GeTe-based Phase-change RF Switches and MMICs," in 2017 IEEE MTT-S International Microwave Symposium (IMS), 4-9 June 2017.

[5] [5] M. Wang, and M. R. Rais-Zadeh, "Directly Heated Four-Terminal Phase Change Switches," in 2014 IEEE MTT-S International Microwave Symposium (IMS), 1-6 June 2014.

[6] [6] M. R. King, et al., "Morphological analysis of GeTe in inline phase change switches," Journal of Applied Physics, vol 118, issue 9, Sept. 2015.

[7] [7] J-S. Moon, et al., "10.6 THz Figure-of-Merit Phase-change RF Switches with Embedded Micro-heater," in 2015 IEEE $15^{\text {th }}$ Topical Meeting on Silicon Monolithic Integrated Circuit in RF Systems (SiRF) 26-28 Jan 2015.

[8] [8] Mennai, et al., "Bistable RF Switches Using $\mathrm{Ge}_{2} \mathrm{Sb}_{2} \mathrm{Te}_{5}$ Phase Change Material," in 2015 IEEE European Microwave Conference, Paris, 6 - 11 Sept 2015.

[9] [9] Mennai, et al., "High Cut-off Frequency RF Switches integrating a Metal-Insulator Transition Material," in, 2015 IEEE MTT-S International Microwave Symposium (IMS), Phoenix, 17 - 22 May 2015. 